\title{
Mechanical characterization of dry-stack masonry made of CEBs stabilised with alkaline activation
}

Rui A. Silva ${ }^{\mathrm{a}, \uparrow}$, Edgar Soares ${ }^{\mathrm{a}}$, Daniel V. Oliveira ${ }^{\mathrm{a}}$, Tiago Miranda ${ }^{\mathrm{a}}$, Nuno M. Cristelo ${ }^{\mathrm{b}}$, Dinis Leitão $^{c}$

${ }^{a}$ ISISE, University of Minho, Department of Civil Engineering, Guimarães, Portugal

${ }^{b}$ C-MADE, University of Trás-os-Montes e Alto Douro, School of Sciences and Technology, Vila Real, Portugal

${ }^{c}$ C-TAC, University of Minho, Department of Civil Engineering, Guimarães, Portugal

\begin{abstract}
The increasing interest on earth construction as a sustainable building solution led to the development of modern earth construction techniques, in particular of masonry made of compressed earth blocks (CEBs). The traditional chemical stabilisation of the soil is a frequently used improvement process. However, such process increases significantly the embodied energy of the CEBs. This paper presents an alternative technique for the stabilisation of CEBs, based on alkali activation of fly ash. The mechanical behaviour of the CEBs and of the respective dry stack masonry is comprehensively investigated through an experimental program, during which this technique proved to be highly effective.
\end{abstract}

\section{Highlights:}

- Manufacturing of CEBs with granitic residual soil requires chemical stabilisation.

- The alkali activation of fly ash was tested as a stabilisation technique.

- The alkali activation improves substantially the strength of the CEBs.

- The stabilisation of CEBs by alkaline activation can be further optimised.

Keywords: CEB, granitic residual soil, mechanical characterization, sustainability, alkaline activation, fly ash

\footnotetext{
† Corresponding author: Department of Civil Engineering, University of Minho, Azurém, 4800-058 Guimarães, Portugal. Tel.: +351 253510 200; fax: +351 253510217 .

E-mail address: ruisilva@civil.uminho.pt
} 


\section{INTRODUCTION}

Raw earth has been used to build sheltering since ancient times [1]. Nowadays, building with earth continues to be a popular solution in many developing countries, such as Peru, Angola, Mozambique, Yemen, Iran, India and China. In fact, this building material constitutes the only feasible alternative in many situations. On the other hand, the use of earth construction fell into disuse during the past century in many developed countries, such as Portugal, Spain, France and Germany. Earth construction has been continuously replaced by modern constructions integrating stronger materials, as reinforced concrete and fired brick, but whose $\mathrm{CO}_{2}$ emissions are also much higher. Despite that, the current importance of earth construction in the World is still very high, as about one fourth of the World's population is estimated to live in earthen dwellings [2]. Furthermore, earth constructions are usually associated to vernacular architecture, since local soils are typically used by local populations. This means that a large diversity of traditional building techniques exist and reflect several features, such as differences between soils, and social, cultural and economic backgrounds of the populations. Among the traditional building techniques, adobe and rammed earth are the most popular ones [1].

Earth construction is a sounding topic nowadays, with growing interest due to the high sustainability (low $\mathrm{CO}_{2}$ emissions and capacity to return the earthen materials back to nature after their life-cycle), thermal and acoustic performance, fire resistance and cost of the raw material (soil) [3]. In fact, earth construction can constitute a feasible solution for a more sustainable construction industry in developed countries. However, the major drawback is that traditional earthen materials are typically considered as non-standard. The great variability and heterogeneity of the properties of the available soils, the lack of quality control in the manufacturing of the earthen materials and in the construction process can be pointed out as the main reasons behind this situation. Furthermore, only few countries issued standards and 
recommendations supporting earth construction (eg.: NZS 4297 [4], NZS 4298 [5], NZS 4299 [6], UNE 41410 [7], HB 195 [8], E.080 [9]), discouraging the design of earth construction by the technical community in countries where these documents are absent. As a consequence, earthen materials are usually associated with poor mechanical properties, low seismic performance and poor durability against water. These materials are also associated to poverty and to the subsistence construction usually found in developing countries. These aspects lead to little acceptance of earth construction by potential owners in developed countries.

Traditional earth construction has been successively subjected to improvement of the earthen materials and building techniques in order to overcome the aforementioned limitations. Masonry built with compressed earth blocks (CEBs) is probably the most relevant case of improvement introduced in the earth construction technology, as these blocks can be seen as an upgrade of the adobes. CEBs are manufactured resorting to specific presses, where the moistened earth is statically compacted in a mould to form the block, which is immediately demoulded and put to dry. This technique was introduced in the nineteen fifties with the development of a specific manual press, which became worldwide known as CINVA-RAM [10]. This procedure allows the strict control of the geometrical features of the CEBs and a significant improvement of the mechanical properties. Nowadays, hydraulic presses can be used instead [11], allowing higher compaction pressure and thus increased mechanical properties [12].

The chemical stabilisation of the soil by addition of cement and lime is often used in the manufacturing of CEBs to increase the mechanical properties of the CEBs and their resistance to water. This procedure is particularly interesting in the cases where the available soil does not meet adequate properties. Nevertheless, the chemical stabilisation is systematically used, even in soils with adequate properties [1]. On the other hand, the addition of cement and lime increases substantially the cost and the embodied energy of the CEBs, making this solution 
less competitive [13-14]. The use of geopolymeric binders obtained from alkaline activation has shown lower $\mathrm{CO}_{2}$ emissions than cement based binders, without compromising properties such as strength and durability [15]. A similar result is expected when applying this technique in the stabilisation of soils. Roughly speaking, the stabilisation process consists in the mixing of the soil with a geopolymer binder, which hardens and forms a matrix that involves and binds the particles in a soil-binder interface that usually delivers strength levels higher than the soil alone. In general terms, the alkaline activation process consists in a reaction between alumina-silicate materials and alkali or alkali earth substances (constituting the alkaline activator), namely: $\mathrm{ROH}, \mathrm{R}(\mathrm{OH})_{2}, \mathrm{R}_{2} \mathrm{CO}_{3}, \mathrm{R}_{2} \mathrm{~S}, \mathrm{Na}_{2} \mathrm{SO}_{4}, \mathrm{CaSO}_{4} \cdot 2 \mathrm{H}_{2} \mathrm{O}, \mathrm{R}_{2}(\mathrm{n}) \mathrm{SiO}_{2}$, in which $\mathrm{R}$ represents an alkaline metal like sodium $\left(\mathrm{Na}^{+}\right)$or potassium $\left(\mathrm{K}^{+}\right)$, or an alkaline earth metal like calcium $\left(\mathrm{Ca}^{2+}\right)$. This reaction is followed by a polycondensation process, in which the silica $\left(\mathrm{SiO}_{2}\right)$ and alumina $\left(\mathrm{AlO}_{4}\right)$ tetrahedra interconnect and share the oxygen ions. The resulting polymer structure of $\mathrm{Al}-\mathrm{O}-\mathrm{Si}$ bonds constitutes the main structure of the hardened geopolymer matrix, which is very similar at a molecular level to natural rocks, sharing their stiffness, durability and strength. Fly ash is probably the most popular alumina-silicate raw source used in alkaline activation, but others can be mentioned such as high-furnace slag and metakaolin [16]. The first two are industrial by-products, meaning that they produce zero $\mathrm{CO}_{2}$ emissions and their use is a way to valorise them in the building industry. Therefore, most of the environmental impact of the alkaline activation technique resides in the production of the alkaline activator compounds, namely sodium hydroxide and sodium silicate [17].

The chemical stabilisation of soils with alkaline activation of fly ash is a topic being studied recently in geotechnical applications [18-19] and in rammed earth construction [20]. The mentioned studies have been able to demonstrate that the stabilisation of soils with this technique can deliver similar or higher mechanical performance than that obtained from the addition of lime or cement [19]. Therefore, the integration of the alkaline activation of fly ash 
in the production of CEBs contributes for the mitigation of the environmental impact associated with more traditional chemical stabilisation (usually achieved with cement), while maintaining the mechanical performance standards. In practical terms, this means that the use of this industrial by-product associated to a control of the incorporated alkaline activator compounds is expected to result in CEBs with lower embodied energy. For instance, Cristelo et al. [21] show that the use of alkaline activation of fly ash in grouts for jet mix columns produces only $77 \%$ of $\mathrm{CO}_{2}$ of the equivalent solution with a cement-based grout.

This paper presents an experimental program where the mechanical behaviour of dry-stack masonry made of CEBs stabilised with alkaline activation of fly ash is assessed in detail. The CEBs were manufactured with granitic residual soil (GRS), typical from northern Portugal, and using two different percentages of fly ash (10\% and 15\%). The individual CEBs were tested under compression and three-point bending (in dry and saturated conditions). The respective masonry was additionally tested for compression and shear behaviour.

\section{EXPERIMENTAL PROGRAM}

\subsection{Geometry of the CEBs and masonry system}

The geometry of the CEBs and the respective building system was based on an output from a previous partnership between the University of Minho and the company Mota-Engil SA. The aim of the project was the development of a simple and innovative solution for the construction of sustainable buildings in seismic countries, which took Malawi as a case study [22]. The geometry of the CEBs consists in a hollow block, see Fig. 1, which allows to build single- and double-leaf walls. According to Minke [23] and the Auroville Earth Institute [24], this type of CEB is recommended for regions with non-negligible seismic hazard, because the holes allow the introduction of vertical reinforcement and to decrease the self-weight of the 
blocks. The masonry built with these CEBs consists in a dry-stack interlocking system, relying on a docking mechanical connection (indentation) between CEBs, which does not require the use of mortared joints. This last feature allows a simpler building process, which promotes faster building processes and lower building costs. Further information on the constructive system is addressed in Ramos et al. [22].

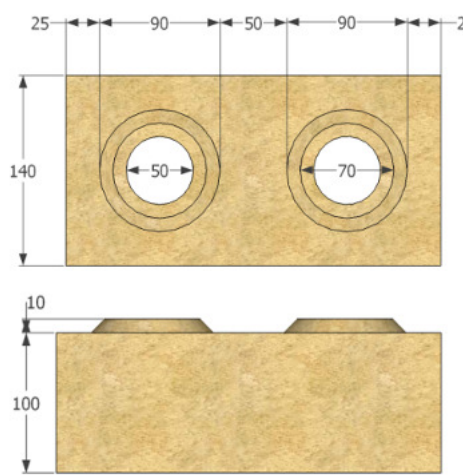

(a)

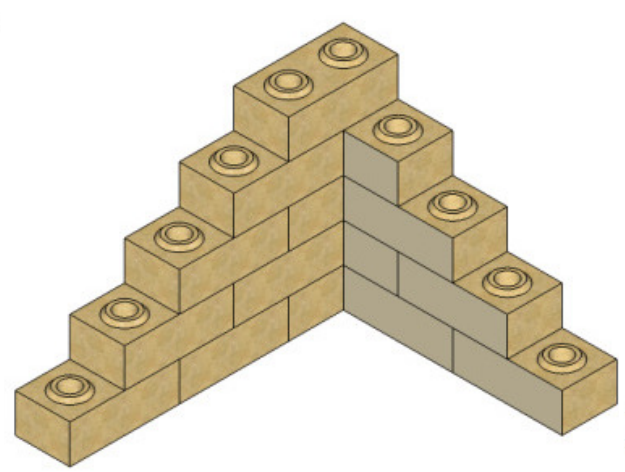

(b)

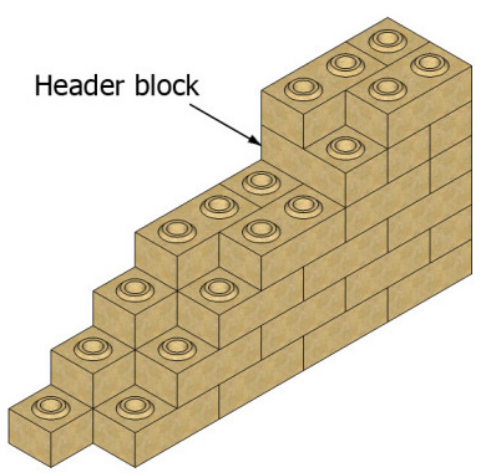

(c)

Fig. 1 - Dry-stack interlocking CEBs masonry system [25]: (a) dimensions of the block (in mm); (b) single-leaf wall; (c) double leaf-wall.

\subsection{Materials}

\subsubsection{Soil}

The soil used in the manufacturing of the CEBs was collected in Guimarães (northern Portugal) and its geotechnical properties were characterized in terms of particle size distribution (PSD) [26], Atterberg limits [27] and Proctor compaction parameters, namely maximum dry density and optimum water content [28]. These properties were then compared with some international documents (standards and recommendations) regulating earth construction in order to conclude about the suitability of the soil for manufacturing unstabilised CEBs $[1,7-8,11]$. It should be noted that Portugal has not issued any standard regarding earth construction so far. 
Fig. 2 presents the PSD curve of the soil and compares it with the envelope provided by Viana da Fonseca [29], regarding GRS from Porto, also located in northern Portugal. In general, the PSD curve of the soil fits within the envelope, meaning that both soils are similar.

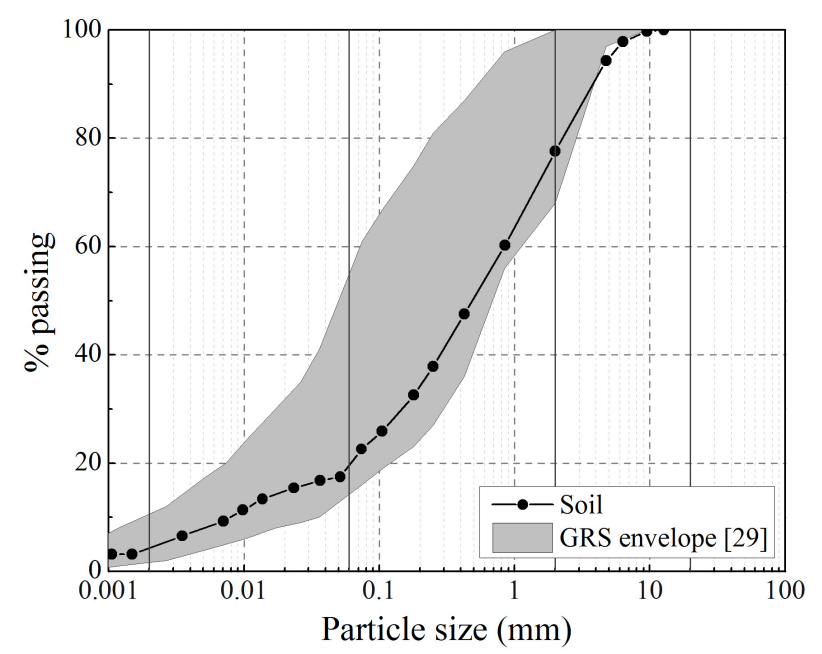

Fig. 2 - PSD curve of the soil and comparison with the envelope presented by Viana da Fonseca [29] for GRS from Porto (northern Portugal).

In Fig. 3, the obtained PSD curve is plotted against envelopes relative to the manufacturing of CEBs, recommended by Houben and Guillaud [1] and by the standard UNE 41410 [7]. In both cases the low fines' content is highlighted, particularly its clay fraction of $4 \%$ ( $\leq$ $0.002 \mathrm{~mm}$ ). The clay content of the soil is clearly inferior to the minimum values recommended by most of the documents regulating CEB construction. For instance, the HB 195 [8] recommends a soil with a minimum clay percentage of about $10 \%$ in order to manufacture unstabilised CEBs. The UNE 41410 [7] requires the same minimum percentage, but a more restrictive criterion is given by discarding the use of any soil with inferior clay percentage. Even in the case of stabilised CEBs, the less restrictive HB 195 [8] recommends a clay percentage higher than 5\%. In practical terms, the low clay percentage of the soil means that the CEBs may experience insufficient strength and resistance against water. Furthermore, problems in the manufacturing of the CEBs are also expected in terms of productivity. The initial cohesion provided by the clay fraction might be insufficient to allow the immediate handling of the blocks. Regarding the maximum particle size of the available soil, it was 
concluded that it is inferior to the $25 \mathrm{~mm}$ and $20 \mathrm{~mm}$ limits, as recommended by HB 195 [8] and UNE 41410 [7], respectively, thus not requiring sieving.

As for the Atterberg limits, the liquid limit (LL) of the soil is approximately $28 \%$ and the plastic limit (PL) could not be determined, meaning that the soil is classified, in terms of plasticity, as non-plastic. This lack of plasticity of the soil indicates insufficient clay content, confirming its unsuitability.

The maximum dry density $\left(\gamma_{d}\right)$ and optimum water content $(\mathrm{OWC})$ are $1.71 \mathrm{~g} / \mathrm{cm}^{3}$ and $12 \%$, respectively. According to Doat et al. [11], the dry density found corresponds to a low value, which is expected to result in an earthen material with fairly poor performance $\left(1.65 \mathrm{~g} / \mathrm{cm}^{3}<\gamma_{d}<1.76 \mathrm{~g} / \mathrm{cm}^{3}\right)$. In fact, the unconfined compressive strength of the soil was tested in a previous work [20], where the average value obtained $\left(0.43 \mathrm{~N} / \mathrm{mm}^{2}\right)$ was very low. Therefore, the soil is unsuitable for manufacturing unstabilised CEBs and its use would require forcibly chemical stabilisation. As stated before, the chemical stabilisation of the CEBs tested in this experimental program was carried out by means of a geopolymer binder resulting from the alkaline activation of fly ash, whose constituting materials are described in the following sections. The soil incorporated in the manufacturing of the CEBs was air dried in advance, and no sieving was performed.

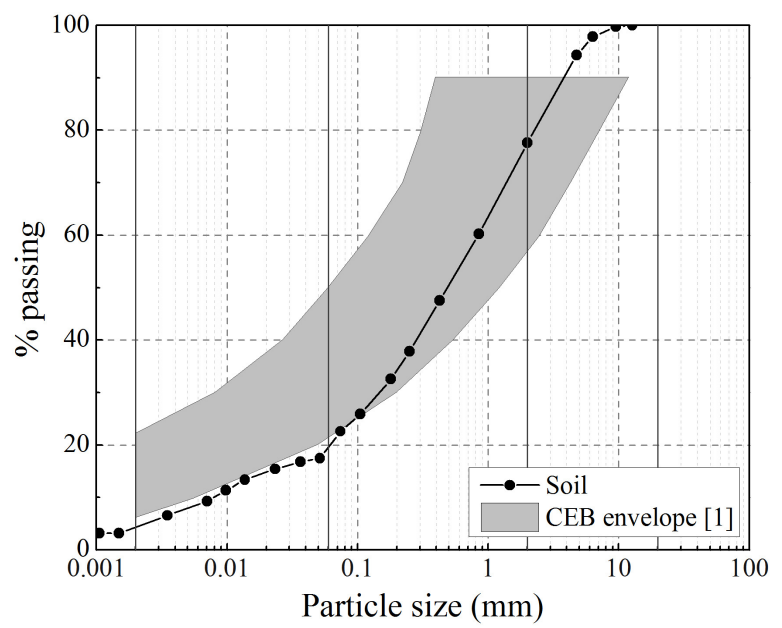

(a)

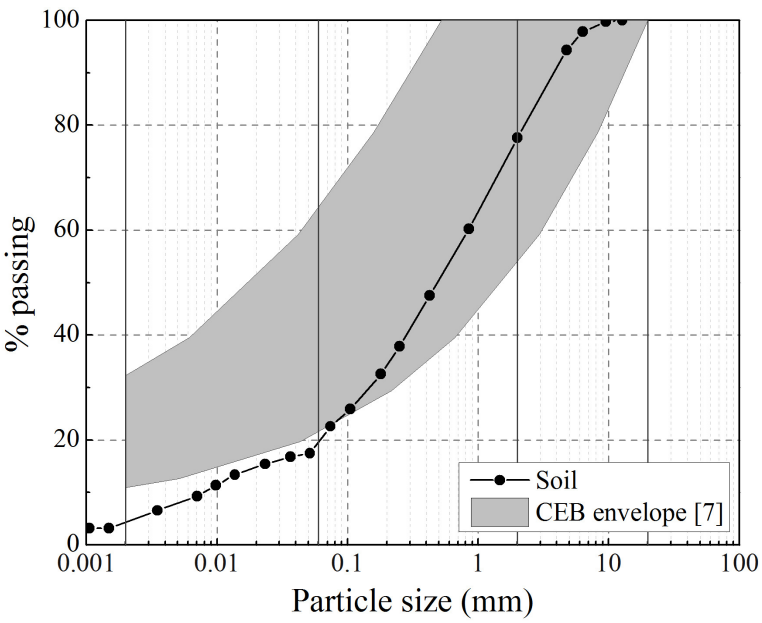

(b)

Fig. 3 - Comparison between the PSD curve of the soil and the envelopes for CEB construction recommended by: (a) Houben and Guillaud [1]; (b) UNE 41410 [7]. 


\subsubsection{Flyash}

The fly ash used in the stabilisation of the CEBs was obtained from a Portuguese thermoelectric power plant (PEGOP). The chemical composition of the fly ash was determined by means of EDS analysis and is presented in Table 1. Three different samples were used to perform the EDS analysis, and 10 acquisition points were considered per sample. The values presented are the average of those 30 acquisition points. The fly ash is characterized by a mass of silica and alumina of about $71 \%$ and a calcium content low enough to classify it as type $\mathrm{F}(<5 \%)$. A scanning electron microscopy (SEM) image of the fly ash is presented in Fig. 4, showing the spherical shape of the particles, with an average diameter estimated at about

\section{$11.64 \mu \mathrm{m}$.}

Table 1 - Chemical composition of the fly ash (from EDS analysis).

\begin{tabular}{ccccccccccc}
\hline Element & $\mathrm{Si}$ & $\mathrm{Al}$ & $\mathrm{Na}$ & $\mathrm{Mg}$ & $\mathrm{P}$ & $\mathrm{S}$ & $\mathrm{K}$ & $\mathrm{Ca}$ & $\mathrm{Ti}$ & $\mathrm{Fe}$ \\
\hline$(\%)$ & 48.8 & 21.8 & 1.3 & 1.6 & 0.6 & 1.2 & 4.4 & 3.9 & 1.8 & 14.7 \\
\hline
\end{tabular}

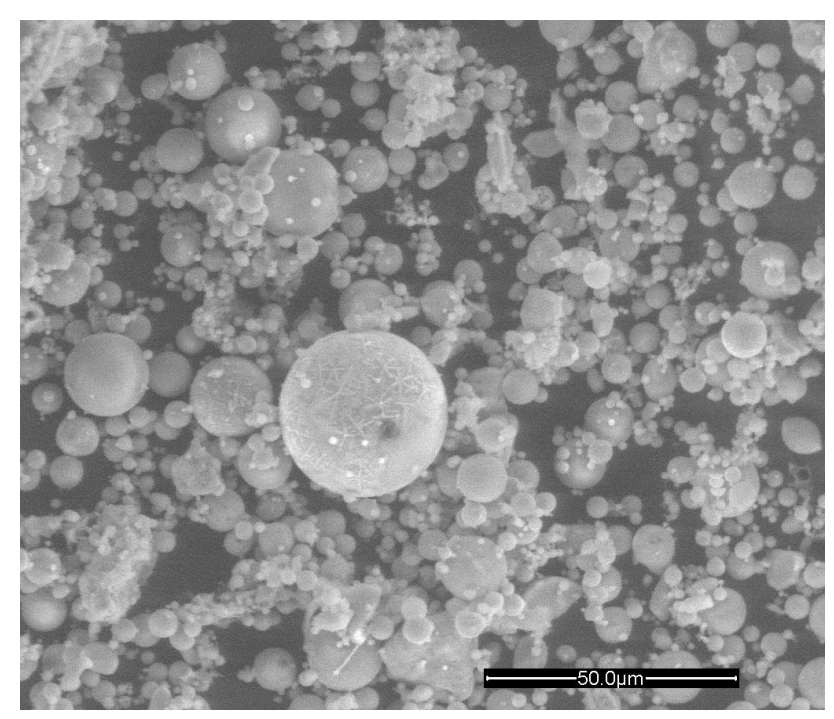

Fig. 4 - SEM image of the fly ash [30].

\subsubsection{Alkaline activator}

The alkaline activator was fabricated by mixing a solution of sodium hydroxide with a solution of sodium silicate, in a 2:1 proportion, respectively. The sodium hydroxide was 
originally acquired in flake form, with a density of $2.13 \mathrm{~g} / \mathrm{cm}^{3}$ at $20^{\circ} \mathrm{C}$, and $95-99 \%$ purity, and was dissolved in water to achieve a concentration of 12.5 molal. The sodium silicate was acquired in solution form, with a density of $1.45 \mathrm{~g} / \mathrm{cm}^{3}$, a sodium oxide $\left(\mathrm{Na}_{2} \mathrm{O}\right)$ content of $13 \%$ and $\mathrm{SiO}_{2}: \mathrm{Na}_{2} \mathrm{O}$ ratio of about 2 .

\subsection{Manufacturing of CEBs}

The two compositions of the mixtures used in the manufacturing of the CEBs are summarized in Table 2. These mixtures were selected from a set of trial-and-error mixtures tested in a previous research work [31], where SFA10 and SFA15 seemed to present adequate workability and mechanical strength for manufacturing CEBs. It should be noted that the incorporated percentage of fly ash is the main variable distinguishing both mixtures, where SFA10 and SFA15 incorporate $10 \%$ and $15 \%$, respectively. Furthermore, the activator/fly ash ratio was defined to be slightly higher than the OWC of the soil in order to take into account the effect of the addition of the fine particles of fly ash in the workability of the mixtures.

Table 2 - Composition of the mixtures used in the manufacturing of the CEBs.

\begin{tabular}{ccccc}
\hline Mixture & Soil (wt.\%) & Fly ash (wt.\%) & Activator/solids (wt.\%) & $\mathrm{Na}_{2} \mathrm{O} / \mathrm{fly}$ ash (-) \\
\hline SFA10 & 90.0 & 10.0 & 13.4 & 0.250 \\
SFA15 & 85.0 & 15.0 & 13.7 & 0.170 \\
\hline
\end{tabular}

The CEBs were manufactured using a Terstaram manual press (Fig. 5a), which allows applying a pressure higher than $2 \mathrm{~N} / \mathrm{mm}^{2}$. The mixtures were prepared in a vertical shaft mixer with free spinning trident paddles. The soil and the fly ash were first dry-mixed until total homogenisation was reached $(\sim 5 \mathrm{~min})$. Then, all the activator was added and the mixing continued until homogenisation occurred again $(\sim 5 \mathrm{~min})$. Each mixture was then used to prepare a batch of ten CEBs. Production control was made in terms of weight of mixture required to perform each $\mathrm{CEB}$, instead of using the respective volume, aiming the minimisation of the CEBs properties' variability. 
After compaction, the CEBs were left to cure on the floor for about 3 days and then were packed until testing. The curing of the CEBs occurred under laboratory conditions at a temperature of $20 \pm 2^{\circ} \mathrm{C}$ and exposed to air. This resulted in the occurrence of some efflorescence at the exposed surfaces of the CEBs, as a consequence of the sodium carbonation. Such behaviour seemed to have only a slight visual impact on the colour, changing from dark grey to light grey. A total of 80 CEBs per mixture were produced.

After compaction, it was possible to handle immediately the CEBs of both mixtures (Fig. 5b), despite their slightly dry appearance not allowing the execution of a successful trial of the drop ball [5]. This means that this typical test, used to calibrate the consistency at the start of the compaction, is not adequate for these mixtures. Furthermore, the adopted percentages of fly ash allowed to achieve adequate fraction of fines required for the production of CEBs. It should be noted that mixtures with less than $10 \%$ of fly ash would not allow the manufacture of the CEBs. This conclusion is supported by the fact that some CEBs made with mixture SFA10 crumbled when handled.

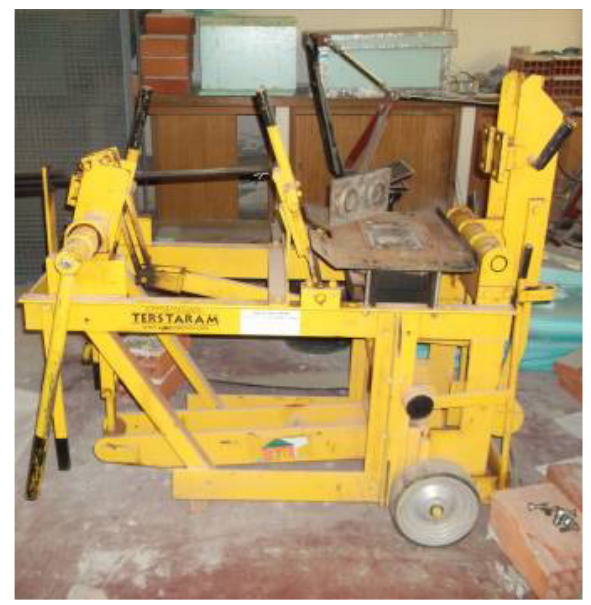

(a)

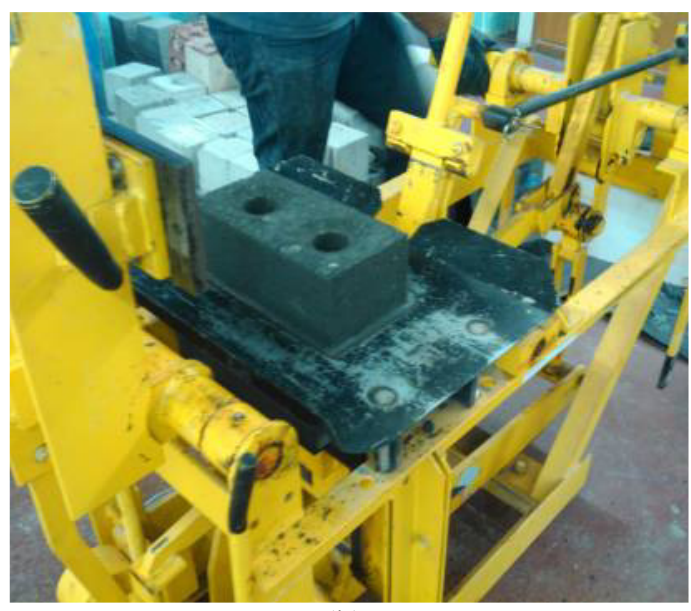

(b)

Fig. 5 - Manufacturing of the CEBs: (a) Terstaram press; (b) CEB after compaction. 


\subsection{Testing procedure}

\subsubsection{Methodology}

The experimental program included the testing of individual CEBs and of single-leaf drystack prisms, after a curing period of 180 days. The CEBs were tested individually for compression and flexural strength (three-point bending test), while the prisms were tested under compression and shear loading. The testing of single CEBs occurred in two different conditions, since some specimens were submerged in water for $24 \mathrm{~h}$ prior to the test (up until 30 min before the test), while the remaining blocks were tested in curing conditions.

\subsubsection{Compression tests (CEBs)}

The compression tests of single CEBs were carried out according to EN 772-1 [32], but the load was applied under displacement control at a rate of about $4 \mu \mathrm{m} / \mathrm{s}$. Four specimens were tested for each mixture and moisture condition (air dry and saturated), in a total of sixteen. The top and bottom platens from the press mould were used as testing platens in order to ovoid cutting and capping the specimens, see also Fig. 1. These platens have the same shape of the CEBs, meaning that they are able to distribute uniformly the load on the top and bottom surfaces of the specimens (Fig. 6a).

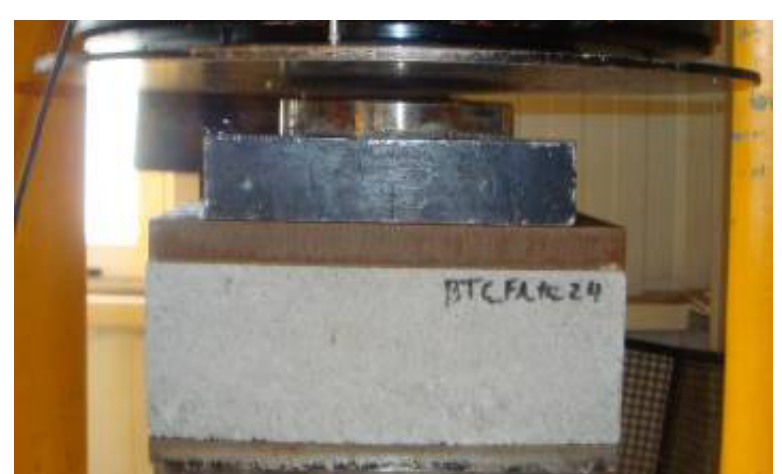

(a)

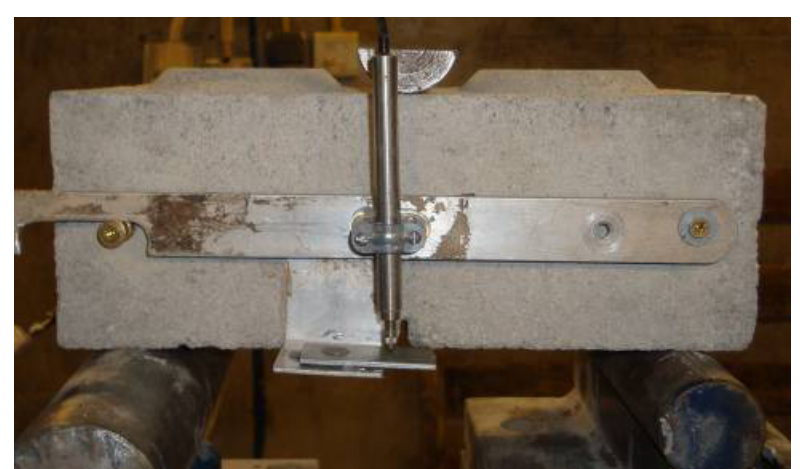

(b)

Fig. 6 - Testing of the individual CEBs under: (a) compression; (b) three-point bending. 


\subsubsection{Three-point bending tests (CEBs)}

The three-point bending tests were carried out according to EN 772-6 [33], but adjustments to the setup were carried out by taking into account the HB 195 [8]. A small notch was made on the CEBs surface before testing, resorting to a circular saw operated in dry conditions. The notch depth and width were of about $10 \mathrm{~mm}$ and $3.5 \mathrm{~mm}$, respectively. This procedure aimed to force the failure surface to occur at middle span, therefore avoiding the hollow sections. The specimens were supported by cylindrical metallic rollers, featuring a $220 \mathrm{~mm}$ span. The load was applied at middle span, under displacement control at a rate of about $2 \mu \mathrm{m} / \mathrm{s}$. The deflection at middle span and the crack opening at the notch were measured by means of Linear Variable Differential Transducers (LVDTs), see Fig. 6b. Four CEBs were tested for each composition and moisture condition (air dry and saturated), in a total of sixteen specimens.

\subsubsection{Compression tests (prisms)}

The compression behaviour of the CEB masonry of both mixtures was assessed by means of compression tests on dry-stack prisms of five blocks, with average dimensions of about $280 \times 500 \times 100 \mathrm{~mm}^{3}$ (width $\mathrm{x}$ height $\mathrm{x}$ thickness). The slenderness of the prisms was of 5:1.4, meaning that the confinement effect introduced by the testing platens is practically insignificant. The testing of this type of arrangement, when compared with that of a full wall, has the advantage of being both simpler to install and to demand a lower loading capacity. On the other hand, it should be noted that the prism specimens are not totally representative of the masonry pattern. The tests were carried out according to ASTM C1314-03b [34], but the load was applied under displacement control at a rate of about $5 \mu \mathrm{m} / \mathrm{s}$. The platens from the mould of the press were also used in this test. Four prisms were tested for each mixture, in a total of eight. Only the air dry condition was taken into account for this case. The vertical 
displacements were measured between the second and the fourth block by means of two LVDTs placed on each face of the prism (see Fig. 7a).

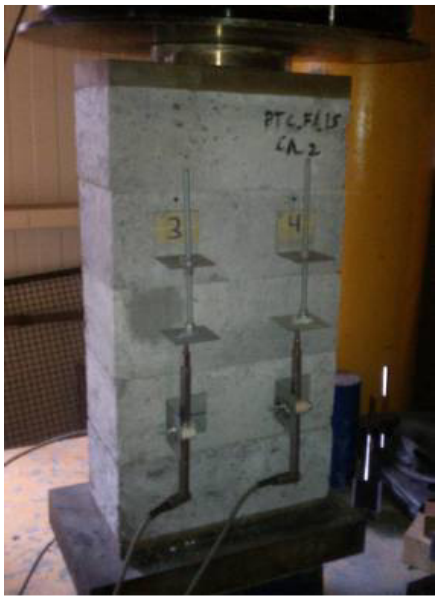

(a)

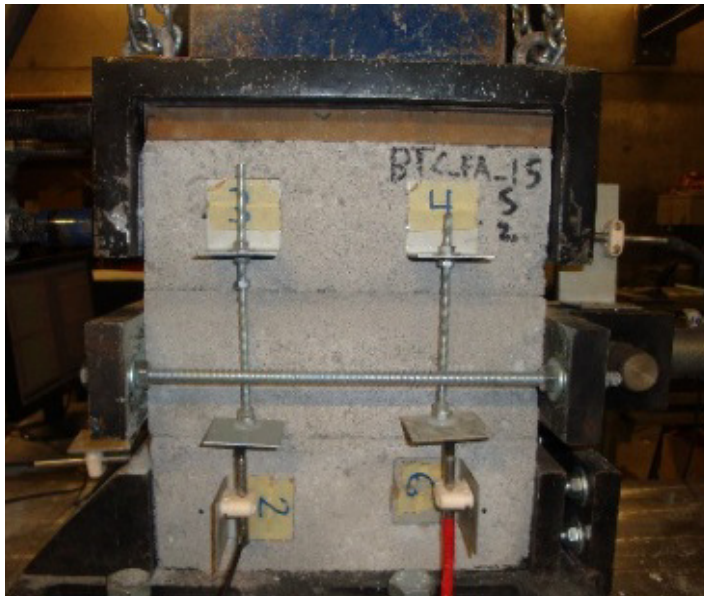

(b)

Fig. 7 - Testing of the CEBs masonry prisms under: (a) compression; (b) shear.

\subsubsection{Shear tests (prisms)}

The shear behaviour of the CEB masonry of both mixtures was assessed by means of shear tests on dry-stack prisms of three CEBs, with average dimensions of about $280 \times 300 \times 100 \mathrm{~mm}^{3}$ (width $\mathrm{x}$ height $\mathrm{x}$ thickness) (see Fig. 7b). The tests were carried out according to EN 1052-3 [35], using three levels of pre-compression stress, namely $0.20 \mathrm{~N} / \mathrm{mm}^{2}, \quad 0.60 \mathrm{~N} / \mathrm{mm}^{2}$ and $0.85 \mathrm{~N} / \mathrm{mm}^{2}$. The first two levels are specified in the aforementioned standard for masonry units with compressive strength higher than $10 \mathrm{~N} / \mathrm{mm}^{2}$, while the third level was reduced relatively to the standard due to load limitations of the axial actuator (pre-compression stress). The shear load was applied by means of an actuator parallel to the joints under displacement control at a rate of about $10 \mu \mathrm{m} / \mathrm{s}$. The relative shear displacement of the middle block was measured by means of two LVDTs, while the axial displacements between the top and bottom blocks were measured by means of two LVDTs attached on each face of the prism. Four prisms were tested for each mixture and level of precompression stress, in a total of twenty four specimens. 


\section{RESULTS AND DISCUSSION}

\subsection{Compression tests (CEBs)}

Table 3 presents the results of the compression tests carried out on the single CEBs, where $\gamma_{b}$ is the air dry density of the blocks, $f_{c, u}^{d}$ is the average compressive strength of the specimens tested under air dry condition and $f_{c, u}^{s}$ is the average compressive strength of the specimens tested under saturated condition. It should be noted that all stress values presented in the paper were computed by taking into account the net area of the CEBs. The typical failure mode of the specimens was characterized by the formation of a pyramidal-trunk, which is explained by the confinement introduced by the loading platens (Fig. 8).

Table 3 - Results of the compression tests on single CEBs (the average values (4 specimens) are given and coefficient of variation is presented in brackets).

\begin{tabular}{ccccc}
\hline Mixture & $\gamma_{b}\left(\mathrm{~kg} / \mathrm{m}^{3}\right)$ & $f_{c, u}^{d}\left(\mathrm{~N} / \mathrm{mm}^{2}\right)$ & $f^{s}{ }_{c, u}\left(\mathrm{~N} / \mathrm{mm}^{2}\right)$ & $f^{s}{ }_{c, u} / f^{d}{ }_{c, u}$ \\
\hline SFA10 & $1810(1 \%)$ & $8.8(11 \%)$ & $5.6(10 \%)$ & 0.64 \\
SFA15 & $1854(1 \%)$ & $12.0(8 \%)$ & $8.0(21 \%)$ & 0.67 \\
\hline
\end{tabular}

The CEBs manufactured with mixture SFA15 obtained higher compressive strength values than those obtained by mixture SFA10, namely 1.36 and 1.42 times higher for $f_{c, u}^{d}$ and $f_{c, u}^{s}$, respectively. The higher performance of mixture SFA15 is mainly explained by its higher percentage of incorporated geolpolymer binder and, in addition, by the higher density of the respective blocks. The low values of the coefficient of variation are also worth to be mentioned, since this means that the stabilisation process was capable of mitigating the intrinsic variability of soil-based products.

With respect to the CEBs tested under saturated condition, the water intake was, on average, of about $5.5 \%$ and $6.5 \%$ for the mixtures SFA10 and SFA15, respectively. This means that the open porosity of the CEBs of both mixtures is similar and not very high. The reduction of the compressive strength in saturated conditions was also similar in both mixtures, namely 
0.64 and 0.67 times for mixtures SFA10 and SFA15, respectively. Both cases correspond to an important decrease in strength. Nevertheless, the minimum value obtained for $f_{c, u}^{s}$ was of about $4.9 \mathrm{~N} / \mathrm{mm}^{2}$ (SFA10).

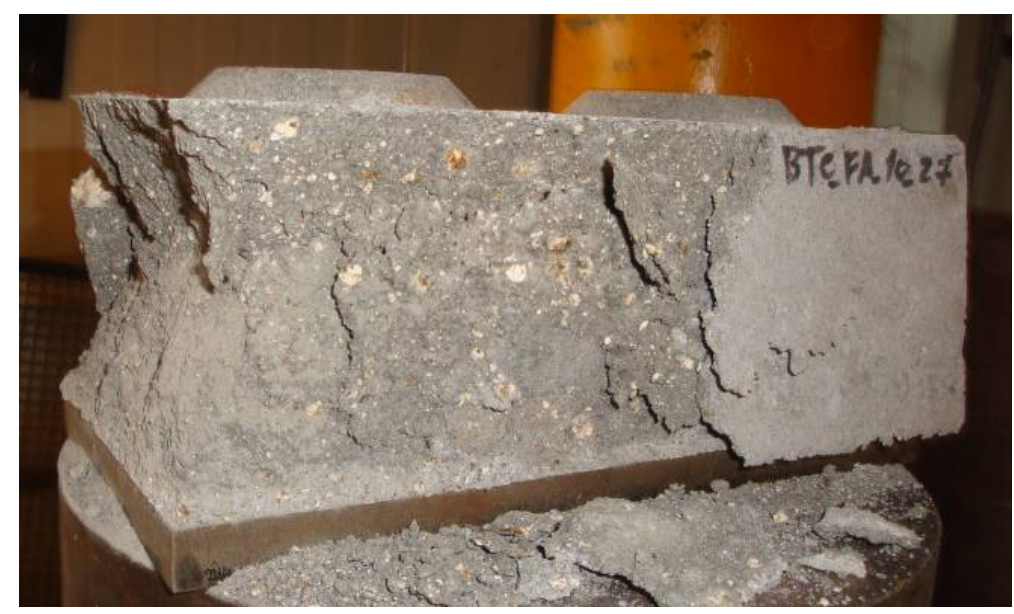

Fig. 8 - Typical failure mode of the single CEBs tested under compression.

In general, common sense indicates that the minimum value of the compressive strength of earthen materials (dry) should not be less than $2 \mathrm{~N} / \mathrm{mm}^{2}$ [1], which is a requirement respected by the CEBs tested. In fact, international documents regulating CEBs masonry construction can be less demanding. For instance, the New Zealand standard NZS 4298 [5] requires a minimum compressive strength of about $1.52 \mathrm{~N} / \mathrm{mm}^{2}$ (it takes into account the aspect ratio of the CEB) for CEBs used in standard grade earth constructions. The Spanish standard UNE 41410 [7] follows a similar trend, since it requires that the lowest class provided (BTC 1) delivers a normalized compressive strength (5\% fractile) higher than $1.3 \mathrm{~N} / \mathrm{mm}^{2}$. Still, according to this standard, the highest class provided (BTC 5) requires a normalised compressive strength (5\% fractile) higher than $5 \mathrm{~N} / \mathrm{mm}^{2}$. It should be noted that the normalized compressive strength of each specimen is obtained by multiplying the compressive strength by a shape factor (0.92). Unfortunately, the few tests carried out do not allow performing a reliable statistical analysis to compute the 5\% fractile, as depicted in UNE 41410 [7]. Nevertheless, the lowest value obtained for the normalized strength was of about $7.3 \mathrm{~N} / \mathrm{mm}^{2}$ (mixture SFA10), meaning that CEBs of both mixtures can be classified as BTC 5. 
The results obtained show that the compressive strength of the blocks tested is substantially higher than that of typical CEBs. For example, for CEBs stabilised with 5-10\% cement, Walker and Stace [36] reported compressive strength values varying between $0.30 \mathrm{~N} / \mathrm{mm}^{2}$ and $7.11 \mathrm{~N} / \mathrm{mm}^{2}$. Moreover, there is still a large margin to optimise the composition of the alkaline activator, in order to reduce the cost and the environmental impact of the stabilisation solution, and still meet the mechanical demands. On the other hand, the levels of compressive strength of the CEBs tested may compete with those of standard masonry units in terms of mechanical performance. For instance, Mohamad [37] reported that the concrete block units found in the USA and Brazilian markets present compressive strength values higher than $4.5 \mathrm{~N} / \mathrm{mm}^{2}$. Thus, the performance obtained for the CEBs unravels the potential of the use of the alkaline activation in the industry for production of masonry units.

\subsection{Three-point bending tests (CEBs)}

Table 4 presents the results of the three-point bending tests carried out on single CEBs, where $f_{b, u}^{d}$ is the average flexural strength of the specimens tested under air dry condition and $f_{b, u}^{s}$ is the average flexural strength of the specimens tested under saturated condition. Both parameters were computed using the expression presented in EN 772-6 [33], taking into account the height reduction introduced by the notch. The failure of all specimens occurred at the middle span cross-section and the failure crack followed a vertical plane, meaning that the notch operated served its purpose (see Fig. 9). In the case of the CEBs tested under air dry condition, failure was brittle, since the specimens failed instantly after a very short plastic phase. On the other hand, the saturation of the CEBs resulted in a softer failure, which was more evidenced in the CEBs with lower strength. This modification of behaviour is shown in Fig. 10, where are presented curves load -deflection and load-crack opening of a selected specimen representing each situation. 
Table 4 - Results of the three-point bending tests on single CEBs (the average values ( 4 specimens) are given and coefficient of variation is presented in brackets).

\begin{tabular}{ccccc}
\hline Mixture & $\gamma_{b}\left(\mathrm{~kg} / \mathrm{m}^{3}\right)$ & $f_{b, u}\left(\mathrm{~N} / \mathrm{mm}^{2}\right)$ & $f_{b, u}^{s}\left(\mathrm{~N} / \mathrm{mm}^{2}\right)$ & $f_{b, u}^{s} / f_{b, u}^{d}$ \\
\hline SFA10 & $1810(1 \%)$ & $1.8(14 \%)$ & $0.7(36 \%)$ & 0.40 \\
SFA15 & $1854(1 \%)$ & $2.3(11 \%)$ & $1.1(9 \%)$ & 0.49 \\
\hline
\end{tabular}

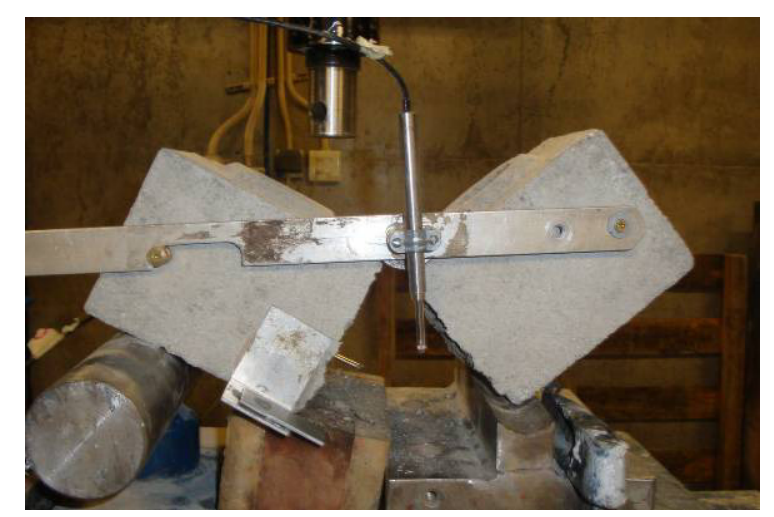

Fig. 9 - Typical failure mode of the single CEBs tested under three-point bending.

Both flexural strength values obtained for CEBs manufactured with mixture SFA15 are higher than those obtained for the CEBs manufactured with mixture SFA10. The same reasons pointed out before for the compressive test results can also be listed for this case, namely the higher percentage of geopolymer binder and the slightly higher density of the CEBs manufactured with mixture SFA15. It should be noted that the low values obtained for the coefficient of variation continue to show the capacity of the stabilisation process in mitigating the effect of the intrinsic variability of the GRS.

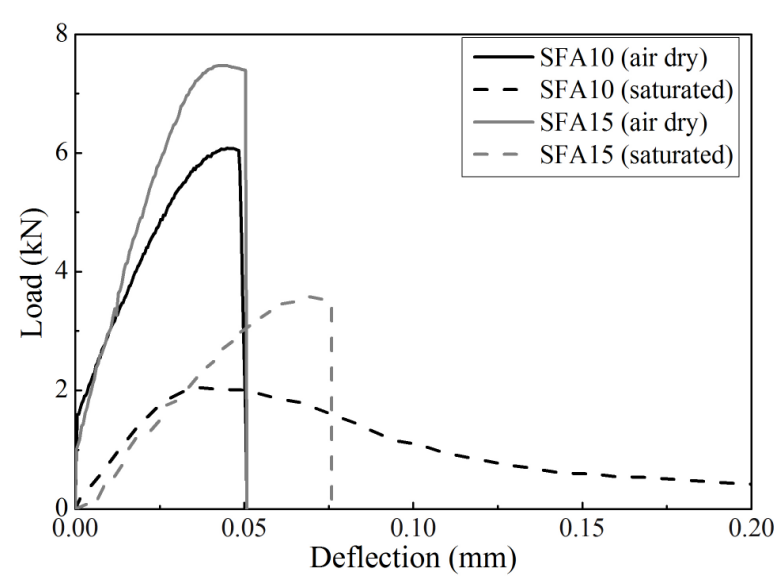

(a)

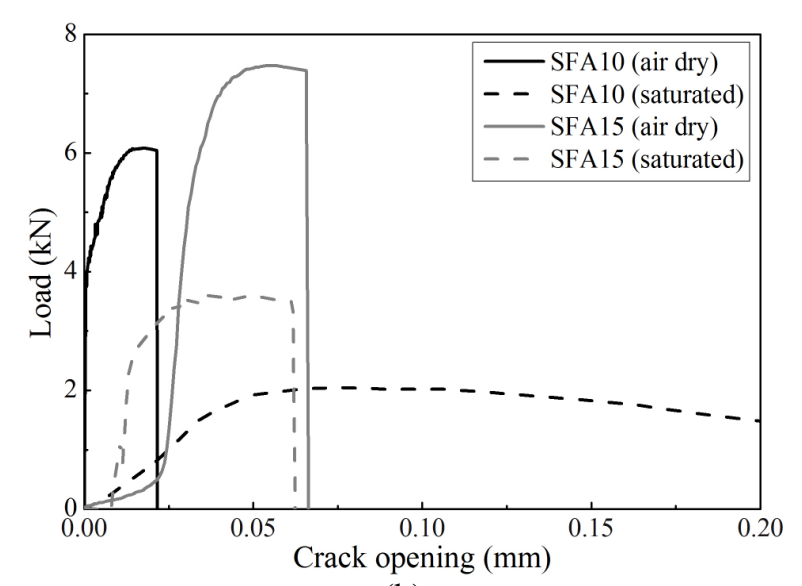

(b)

Fig. 10 - Representative curves of the three-point bending tests (selected specimens): (a) load-deflection; (b) load-crack opening. 
Unlike the compressive strength, the flexural strength parameter of the CEBs deserves little attention in the most relevant international documents regulating earth construction. Nevertheless, according to the NZS 4298 [5], the flexural strength can also be used to verify the minimum strength standards of the CEBs. With this respect, the minimum value required for the flexural strength is of $0.25 \mathrm{~N} / \mathrm{mm}^{2}$, which is a criteria largely exceeded by the CEBs of both mixtures. According to NZS 4297 [4], the compressive strength can be estimated as 3.5 times the flexural strength. This relation corresponds to a safe estimation (underestimation) of the compression strength in this work, since the respective values for mixture SFA10 and SFA15 were $4.9 \mathrm{~N} / \mathrm{mm}^{2}$ and $5.2 \mathrm{~N} / \mathrm{mm}^{2}$.

\subsection{Compression tests (masonry prisms)}

The results of the compression tests carried out on the masonry prisms are summarized in Table 5, in terms of average compressive strength $\left(f_{c, p}\right)$ and average Young's modulus $\left(E_{0, p}\right)$. The last parameter was computed between $5 \%$ and $30 \%$ of the compressive strength by linear fitting of the respective compression stress-axial strain curves, which are presented in Fig. 11. These curves are characterized by an initial adjustment phase, which is related with the accommodation between CEBs at the dry joints. It should be noted that some curves are incomplete due to early detachment of the LVDTs from the blocks caused by damage of the specimens.

Table 5 - Results of the compression tests on the masonry prisms (the average values ( 4 specimens) are given and coefficient of variation is presented in brackets).

\begin{tabular}{cccc}
\hline Mixture & $f_{c, p}\left(\mathrm{~N} / \mathrm{mm}^{2}\right)$ & $E_{0, p}\left(\mathrm{~N} / \mathrm{mm}^{2}\right)$ & $E_{0, p} / f_{c, p}$ \\
\hline SFA10 & $3.3(15 \%)$ & $551(16 \%)$ & 167 \\
SFA15 & $4.6(9 \%)$ & $463(8 \%)$ & 100 \\
\hline
\end{tabular}

As expected, $f_{c, p}$ assumes the highest value for the case of the prisms built with CEBs from mixture SFA15. Furthermore, $f_{c, p}$ is found to be 0.38 and 0.39 times $f_{c, u}^{d}$, respectively for the mixtures SFA10 and SFA15. This relation is very similar in both mixtures, which might 
indicate that the compressive strength of the individual CEBs may provide a good estimation of the compressive strength of the dry-stack prisms built with these CEBs. On the other hand and according to NZS 4297 [4], the compressive strength of the masonry is estimated to be 0.5 times the compressive strength of the CEBs. Therefore, this standard would lead to an overestimation of the compressive strength in this case, with implication on safety if used for design purposes. The lower ratio value obtained from the tests is possibly related with the type of masonry and respective failure mode. The inexistence of mortared joints may introduce localized tensile stress concentrations in the CEBs, which are responsible for weakening the masonry during loading. With respect to $E_{0}$, both mixtures promoted similar values for the respective masonry. However, $E_{0}$ was unexpectedly higher for mixture SFA10, which is probably explained by the fact that the deformation of the prisms is mostly controlled by the dry-stack joints, namely with respect to the adjustment of possible imperfections of the contact surfaces between CEBs (such as loose particles and protuberances). It should also be noted that the standard NZS 4297 [4] provides an overestimation of the Young's modulus as a function of the compressive strength of the CEBs, where the first is assumed to be 300 times the second. This relation is of about 167 and 100 times in the case of mixture SFA10 and SFA15, respectively.

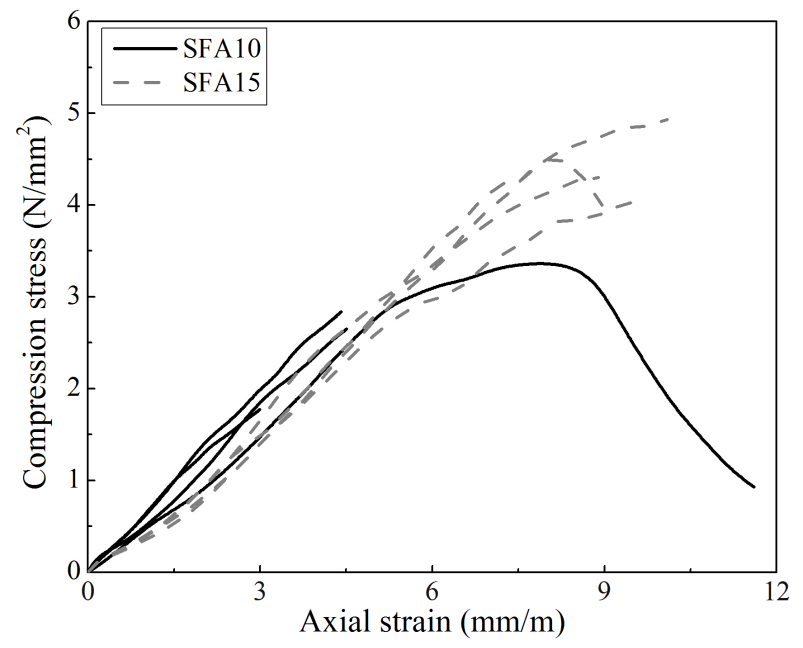

Fig. 11 - Compression stress - axial strain curves of the masonry prisms tested under compression. 
Fig. 12 illustrates the typical failure mode of the masonry prism tested under compression. The failure mode is characterized by distributed cracking in the three middle blocks. The cracks seemed to develop continuously from a block towards the adjacent one, not showing relative displacements at the dry-stack joints. The CEBs in contact with the testing platens presented little cracking, probably due to the confinement effect. Nevertheless, spalling was a common damage in these CEBs. Furthermore, some localised damage was also observed, namely in the form of spalling of the corners of some CEBs and crushing at the horizontal joints. These types of damage were probably a consequence of stress concentrations caused by imperfections of the CEBs at the contact surfaces.
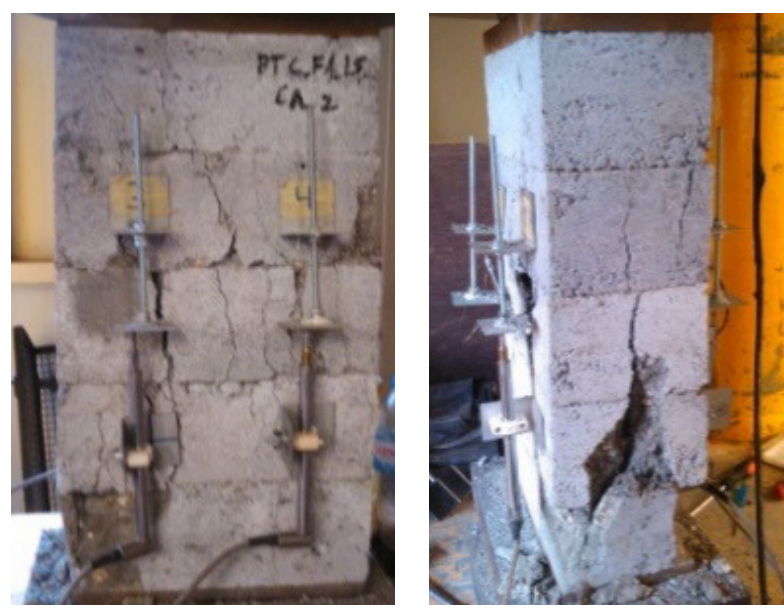

Fig. 12 - Typical failure mode of the masonry prisms tested under compression.

\subsection{Shear tests (masonry prisms)}

The shear stress - shear displacement curves resulting from shear tests are presented in Fig. 13 for selected prisms representing each pre-compression level and mixture. In general, the prisms with lower pre-compression stress exhibit a softer behaviour being capable of sustaining a shear stress value close to the maximum in the post-peak phase. On the other hand, the prisms with higher pre-compression stress exhibit a more fragile behaviour, with significantly stress drops in the post-peak phase. This fragile behaviour is probably a consequence of the occurrence of a higher level damage in the CEBs. 
The relationship between shear strength with the pre-compression level is depicted in Fig. 14 . The prisms built with CEBs from mixture SFA15 exhibit an almost linear relationship, but a less linear relationship was found for the case of mixture SFA10. This unexpected behaviour is thought to be related with the occurrence of excessive crushing and wearing at the contact surfaces between the CEBs of the prisms tested with pre-compression stress of $0.85 \mathrm{~N} / \mathrm{mm}^{2}$. This probably means that this level of pre-compression was excessively high, given the compression strength of the respective CEBs, and that this situation led to a reduction of the shear strength relative to the previous pre-compression level. Despite that, the linear regression applied to the points of the graph show initial shear strength values of about $0.20 \mathrm{~N} / \mathrm{mm}^{2}$ and $0.17 \mathrm{~N} / \mathrm{mm}^{2}$ in the case of mixture SFA10 and SF15, respectively. These non-zero strength values for null compression represent the contribution of the interlocking system for the shear strength of the masonry. Regarding the friction coefficient $(\tan \phi)$, the values obtained were of about 1.20 and 1.07 for peak resistance in the case of mixture SFA10 and SFA15, respectively. These values are significantly higher than 0.4 , proposed in Eurocode 6 [38], which is probably a consequence of the very rough and apparently hard contact surfaces of the blocks and of the progressive failure of the interlocking system.

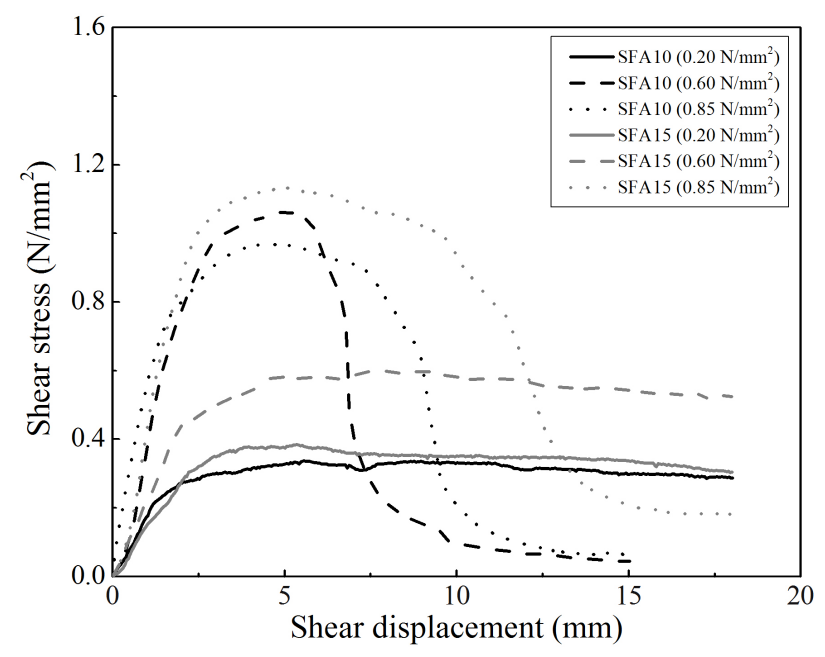

Fig. 13 - Curves shear stress - shear displacement (selected prisms). 


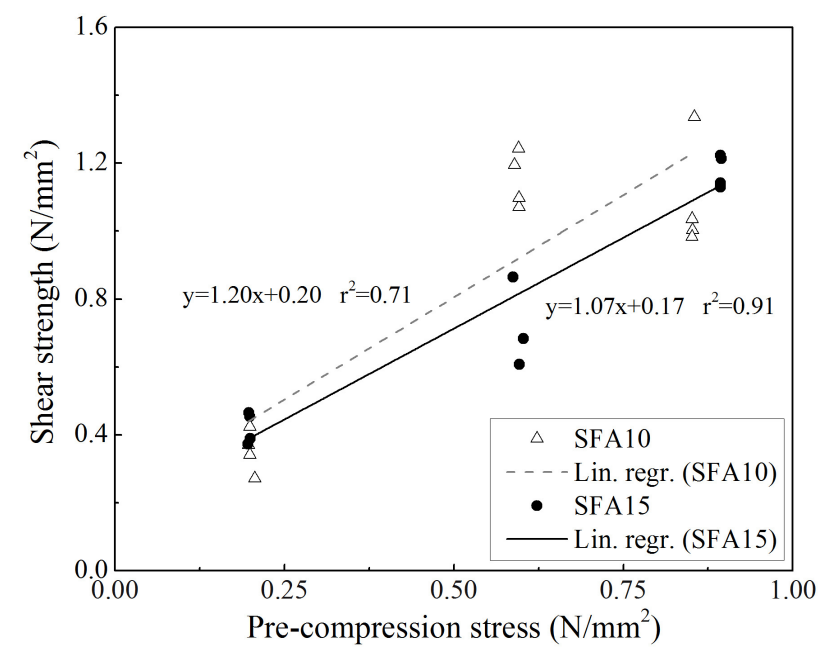

Fig. 14 - Relationship between shear strength and pre-compression stress.

Fig. 15 presents the axial displacement - shear displacement curves of selected prisms representing each pre-compression level and mixture, as well as the respective point of maximum shear stress. The curves resulting from the pre-compression level $0.20 \mathrm{~N} / \mathrm{mm}^{2}$ exhibit a positive although very low dilatancy coefficient (average value of 0.03 at peak shear stress). Within the other two pre-compression levels, dilatancy becomes negative at peak shear stress due to crushing and wearing of the contact surfaces between blocks. Furthermore, the prisms built with CEBs from mixture SFA10 exhibit higher axial displacements than those from mixture SFA15, due to a more severe damage. Fig. 15 also shows that with increasing shear displacement the dilatancy coefficient decreases, for all pre-compression levels.

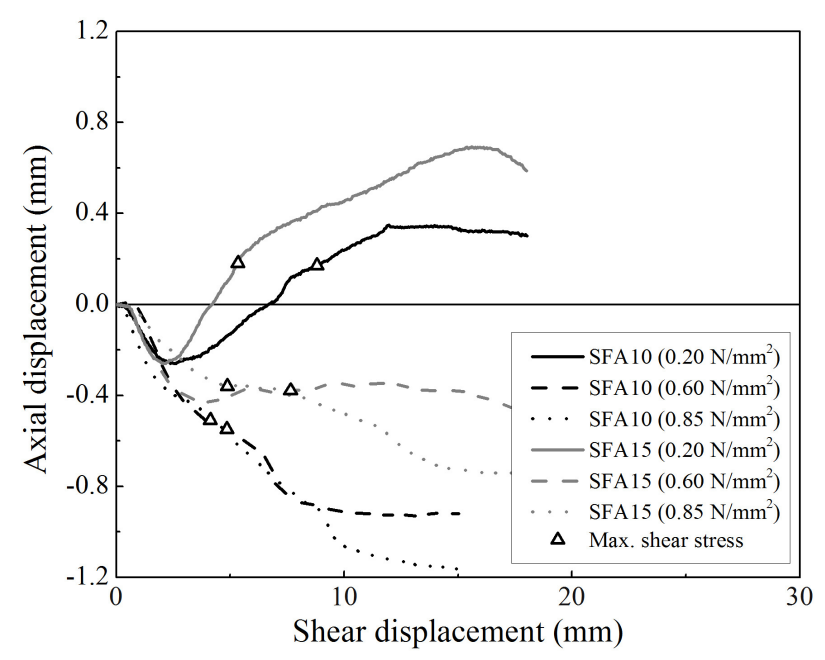

Fig. 15 - Curves axial displacement - shear displacement (selected prisms). 
The values of the dilatancy coefficient were computed for the maximum shear stress and their relationship with the pre-compression stress is depicted in Fig. 16. The dilatancy assumes positive values for the lowest pre-compression stress and negative values for the other two pre-compression levels. The relationship between the dilatancy and the pre-compression stress seems to be almost linear, see also Fig. 16.

The typical failure mode of the prisms is illustrated in Fig. 17, where the intermediate block slides relatively to the top and bottom ones. After testing, the prisms were dismounted to allow the observation of the interlocking system. In general, one or both of the indentations failed during the test at each contact surface. Furthermore, it was possible to observe that the contact between CEBs was not complete and that depended on the pre-compression stress; the higher the pre-compression stress the higher the worn level of the surface. In general, the contact occurred mainly at the borders of the CEBs, explaining the crushing occurring in these regions for the prisms with higher pre-compression levels. Probably, this situation indicates that the CEBs are excessively stiff for being used in dry-stack masonry and that the use of bed joint mortar would improve the shear behaviour under the higher pre-compression stress levels.

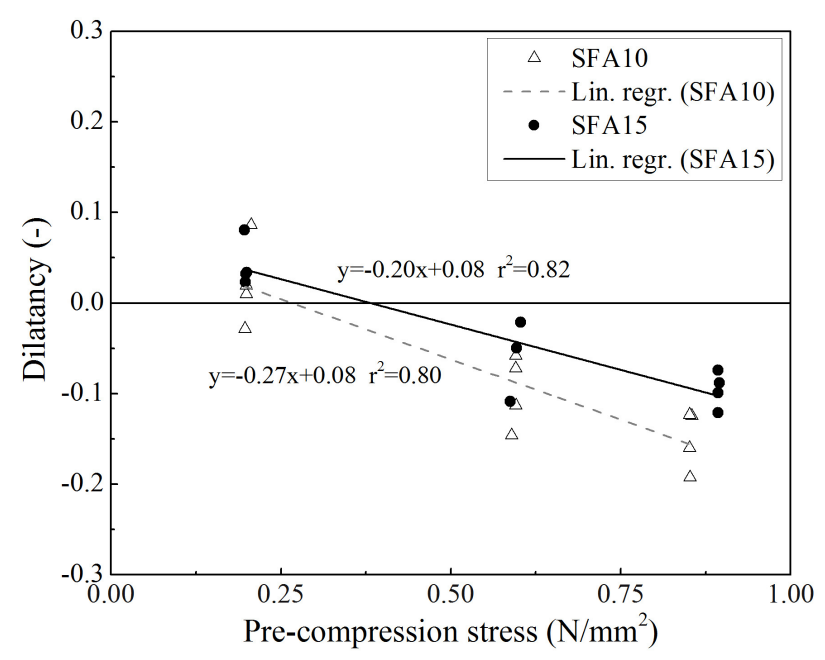

Fig. 16 - Relationship between dilatancy and pre-compression stress. 


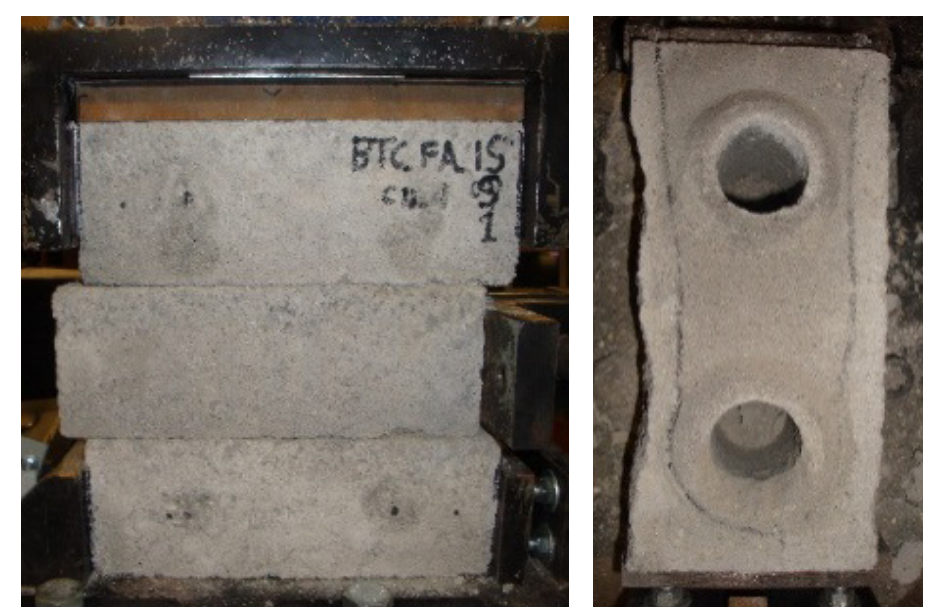

Fig. 17 - Typical failure mode of the masonry prisms tested under shear loading.

\section{CONCLUSIONS}

This paper presents an experimental program where the mechanical behaviour of a solution consisting of dry-stack masonry made from CEBs is assessed. The CEBs were manufactured with a typical GRS from northern Portugal, stabilised by means of alkaline activation of fly ash. Two compositions incorporating different percentages of fly ash were studied (SFA10 and SFA15).

The mechanical tests carried out on single CEBs showed that the higher the percentage of geopolimer binder, the higher the values of the strength parameters. Furthermore, the values obtained for these parameters were shown to be much superior to those required by some international documents regulating earth construction. The mitigation of the intrinsic variability of the GRS on the variability of the mechanical properties of the CEBs was another feature promoted by the stabilisation process which was used. The presence of water was also shown to reduce substantially the values of the strength parameters of the CEBs. Nevertheless, the mechanical performance of the CEBs in saturated conditions was still suitable for earth construction.

The compression tests carried out on the dry-stack masonry prisms showed an important reduction of the compressive strength of the masonry relative to the compressive strength of 
the CEBs. Furthermore, international documents regulating earth construction lead to an overestimation of the compressive strength of the masonry when computed with basis on the strength of the CEBs. This situation can rise design issues, meaning that a reduction factor lower than 0.39 should be adopted for the masonry system here presented.

The shear tests presented some problems related with excessive pre-compression stress on the prisms built with CEBs from mixture SFA10, which led to excessive crushing and wearing of the contact surfaces between CEBs. Nevertheless, the shear parameters obtained (initial shear strength and friction coefficient) were substantially high. Despite that, the contact between CEBs was incomplete, meaning that the use mortared joints is expected to improve the shear behaviour of the masonry. As for the dilatancy behaviour, it was observed an inverse linear relationship between the pre-compression stress level and the dilatancy coefficient, where negative values of this coefficient were found for two of the pre-compression levels.

In general, the alkaline activation of fly ash was shown to promote excellent results regarding the improvement of the mechanical performance of CEBs manufactured with GRS. This means that a large margin for optimization of the mixtures exists, namely with respect to the environmental impact and cost of the solution. Furthermore, other aspects need to be assessed in further investigation, namely with respect to non-mechanical features of the masonry system. These include features such as acoustic and thermal performance of the masonry walls, development and study of compatible renderings, as well as durability assessment.

\section{Acknowledgements}

The authors wish to express their gratitude to Mr. Pedro Esteves for his support in the experimental work and to Eng. Jorge Henriques, on behalf of the company PEGOP - Energia Eléctrica SA, for providing the fly ash. The financial support provided by the Portuguese 
Science and Technology Foundation through the project FCOMP-01-0124-FEDER-028864 (FCT-PTDC/ECM-EST/2396/2012) is also gratefully acknowledged.

\section{References}

[1] Houben H, Guillaud H. (2008) Earth Construction: A Comprehensive Guide. Intermediate Technology Development Group.

[2] Jaquin, P.A. (2014) One third of world's population live in earth buildings? http://historicrammedearth.com/one-third-of-worlds-population-live-in-earth-buildings (accessed on 02/06/2014).

[3] Pacheco-Torgal F, Jalali S. (2012) Earth construction: lessons from the past for future eco-efficient construction. Constr Build Mater; 29:512-519.

[4] Standards New Zealand (1998a). Engineering design of earth buildings (NZS 4297:1998). Standards New Zealand, Wellington.

[5] Standards New Zealand (1998b). Materials and workmanship for earth buildings (NZS 4298:1998). Standards New Zealand, Wellington.

[6] Standards New Zealand (1998c). Earth buildings not requiring specific design (NZS 4299:1998). Standards New Zealand, Wellington.

[7] AENOR (2008). Compressed earth blocks for walls - Definitions, specifications and testing methods (UNE 41410). Asociación Española de Normalización y Certificación, Spain. (in Spanish)

[8] Standards Australia (2002). The Australian earth building handbook (HB 195). Standards Australia, Sydney.

[9] SENCICO (2006). E.080: Adobe. Reglamento Nacional de Construcciones. Lima. (in Spanish)

[10] Barbosa N., Mattone R. (2002) Building with raw earth, I Seminário Ibero-Americano de Construção com terra, Salvador, Brasil, p. 41-50. (in Portuguese)

[11] Doat P, Hays A, Houben H, Matuk S, Vitoux F. (1991) Building with earth. The Mud Village Society, New Delhi.

[12] Gomes I. (2008). Earthquake-Resistant Construction with Raw Earth. Msc. Thesis, Instituto Superior Técnico, Lisbon, Portugal. (in Portuguese)

[13] Reddy B.V.V., Kumar P.P. (2010). Embodied energy in cement stabilised rammed earth walls. Energy and Buildings, 42, p. 380-385. 
[14] Lax C. (2010) Life cycle assessment of rammed earth. Msc. thesis, University of Bath, United Kingdom.

[15] Torgal F.P., Jalali S. (2010) Portland cement versus geopolymeric binders: durability and environmental performance, Teoria e Prática na Engenharia Civil, 15, p. 1-9. (in Portuguese)

[16] Roy D.M. (1999) Alkali-activated cements opportunities and challenges, Cement and Concrete Research, 9 (2), p. 249-254.

[17] Weil M., Dombrowski K., Buchawald A. (2009) Life-cycle analysis of geopolymers. In Geopolymers, Structure, Processing, Properties and Applications, Provis J., Van Deventer J. Ed(s), Woodhead Publishing Limited Abington Hall, Cambridge, UK, p. 194-210.

[18] Cristelo N., Glendinning S., Fernandes L., Teixeira Pinto A. (2012a) Effect of calcium content on soil stabilisation with alkaline activation, Construction and Building Materials, 29, p. 167-174.

[19] Cristelo N., Glendinning S., Miranda T.F., Oliveira D.V., Silva R.A. (2012b) Soil Stabilisation using Alkaline Activation of Fly Ash for Self Compacting Rammed Earth Construction, Construction and Building Materials, 36, p. 727-735.

[20] Silva R.A., Oliveira D.V., Miranda T., Cristelo N., Escobar M.C., Soares, E. (2013). Rammed earth construction with granitic residual soils: The case study of northern Portugal, Construction and Building Materials, 47, p. 181-191.

[21] Cristelo N., Miranda T., Oliveira D.V., Rosa I., Soares E., Coelho P., Fernandes L. (2014). Sustainable Production of Jet Mix Columns using Alkali Activated Industrial Waste Binders. Personal communication submitted to the Journal of Cleaner Production.

[22] Ramos L.F., Mendonça P., Camões A., Sturm T., Eires R., Reis P., Sousa J., Vasconcelos G. (2011) The partition walls of an integrated system of structural masonry made of CEBs, Seminário sobre Paredes Divisórias, Porto, Portugal. (in Portuguese)

[23] Minke G. (2006) Building with earth: Design and technology of a sustainable architecture. BirkhäusePublishers for Architecture, Basel-Berlin-Boston.

[24] AEI (2005). Earthquake resistant buildings with hollow interlocking blocks, Auroville Earth Institute, UNESCO Chair - Earthern Architecture.

[25] Sturm T., Ramos L.F., Lourenço P.B. (2014). Characterization of dry-stack interlocking compressed earth blocks. Materials and Structures, DOI 10.1617/s11527-014-0379-3.

[26] LNEC (1966). LNEC E196: Soils: particle size distribution analysis, Especificação do Laboratório Nacional de Engenharia Civil, Lisbon, Portugal. (in portuguese) 
[27] LNEC (1969). NP 143: Soils: determination of the consistency limits, Laboratório Nacional de Engenharia Civil, Lisbon, Portugal. (in Portuguese)

[28] LNEC (1967). LNEC E197: Soils: compaction test, Especificação do Laboratório Nacional de Engenharia Civil, Lisbon, Portugal. (in Portuguese)

[29] Viana da Fonseca A. (1996) Geomechanics of the granitic residual soils from Porto. Criteria for the design of direct foundations. PhD Thesis, Dept. of Civil Engineering, University of Porto, Portugal; 1996. (in Portuguese)

[30] Cristelo N., Soares E., Rosa I., , Miranda T.F., Oliveira D.V., Silva R.A., Chaves A. (2013) Rheological properties of alkaline activated fly ash used in jet grouting applications, , Construction and Building Materials, 48, p. 925-933.

[31] Soares E. (2013) Improvement of granitic residual soil resorting to the alkali activation of fly ash. Msc. Thesis, University of Trás-os-Montes e Alto Douro, Vila Real, Portugal. (in Portuguese)

[32] CEN (2011) EN 772-1:2011: Methods of test for masonry units. Part 1: Determination of compressive strength, European Committee for Standardization, Brussels.

[33] CEN (2002) EN 772-6:2002: Methods of test for masonry units. Part 6: Determination of bending tensile strength of aggregate concrete masonry units, European Committee for Standardization, Brussels.

[34] ASTM (2003) ASTM C1314-03b: Standard test method for compressive strength of masonry prisms, American Society for Testing and Materials, West Conshohocken, PA.

[35] CEN (2002) EN 1052-3:2002: Methods of test for masonry. Part 3: Determination of initial shear strength, European Committee for Standardization, Brussels.

[36] Walker P.J., Stace T. (1997) Properties of some cement stabilised compressed earth blocks and mortars. Materials and Structures, 30, p. 545-551.

[37] Mohamad G. (2007) Mechanism failure of concrete block masonry under compression. PhD Thesis, University of Minho, Guimarães, Portugal. (in Portuguese)

[38] CEN (2005) EN 1996-1-1:2005: Eurocode 6: design of masonry structures - part 1-1: common rules for reinforced and unreinforced masonry structures, European Committee for Standardization, Brussels. 


\section{LIST OF TABLE CAPTIONS}

Table 1 - Chemical composition of the fly ash (from EDS analysis) ................................... 9

Table 2 - Composition of the mixtures used in the manufacturing of the CEBs.................... 10

Table 3 - Results of the compression tests on single CEBs (the average values (4 specimens) are given and coefficient of variation is presented in brackets)........................................... 15

Table 4 - Results of the three-point bending tests on single CEBs (the average values (4 specimens) are given and coefficient of variation is presented in brackets) 18

Table 5 - Results of the compression tests on the masonry prisms (the average values (4 specimens) are given and coefficient of variation is presented in brackets). 19 


\section{LIST OF FIGURE CAPTIONS}

Fig. 1 - Dry-stack interlocking CEBs masonry system [25]: (a) dimensions of the block (in $\mathrm{mm}$ ); (b) single-leaf wall; (c) double leaf-wall.

Fig. 2 - PSD curve of the soil and comparison with the envelope presented by Viana da Fonseca [29] for GRS from Porto (northern Portugal).

Fig. 3 - Comparison between the PSD curve of the soil and the envelopes for CEB construction recommended by: (a) Houben and Guillaud [1]; (b) UNE 41410 [7]................. 8

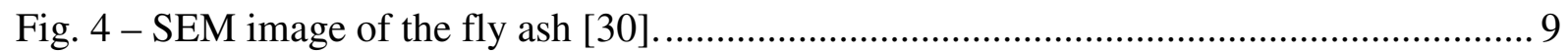

Fig. 5 - Manufacturing of the CEBs: (a) Terstaram press; (b) CEB after compaction............ 11

Fig. 6 - Testing of the individual CEBs under: (a) compression; (b) three-point bending...... 12

Fig. 7 - Testing of the CEBs masonry prisms under: (a) compression; (b) shear. .................. 14

Fig. 8 - Typical failure mode of the single CEBs tested under compression. ........................ 16

Fig. 9 - Typical failure mode of the single CEBs tested under three-point bending............... 18

Fig. 10 - Representative curves of the three-point bending tests (selected specimens): (a)

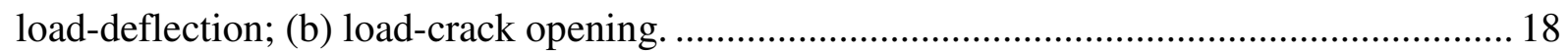

Fig. 11 - Compression stress - axial strain curves of the masonry prisms tested under

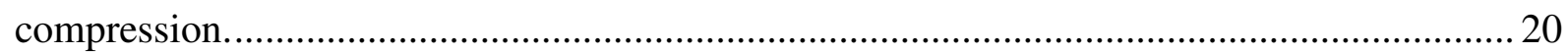

Fig. 12 - Typical failure mode of the masonry prisms tested under compression.................. 21

Fig. 13 - Curves shear stress - shear displacement (selected prisms). ................................. 22

Fig. 14 - Relationship between shear strength and pre-compression stress. ......................... 23

Fig. 15 - Curves axial displacement - shear displacement (selected prisms)........................ 23

Fig. 16 - Relationship between dilatancy and pre-compression stress................................. 24

Fig. 17 - Typical failure mode of the masonry prisms tested under shear loading. ............... 25 